\title{
UNA NUEVA FORMA DE GESTIÓN: LA EVALUACIÓN ${ }^{*}$
}

\author{
Jean-Pierre Faguer ${ }^{* *}$ \\ Gabrielle Balazs
}

\begin{abstract}
Actualmente, el control permanente de los desempeños se tiende a instaurar en todos los lugares de trabajo, en las fábricas, en las oficinas, en los supermercados y también en los empleos subalternos de la actividad intelectual. La incertidumbre, asociada con frecuencia a estas formas de actividad, que obliga a invertir y "desinvertir" continuamente, moviliza, al mismo tiempo, la creencia en el futuro y la amenaza de perder el empleo. La disponibilidad y la flexibilidad suscitan auto-evaluación y reconversión. Las relaciones de trabajo son inseparablemente relaciones de dominación, donde cada puesto, al mismo tiempo que implica el dominio de una competencia técnica específica, requiere las cualidades exigidas ordinariamente al personal.
\end{abstract}

Así, con la informática, hasta del personal subalterno se exige una parte cada vez más importante de actividad de servicio y de "comunicación". Tomándose aparentemente más autónomo, cada asalariado debe acumular las cualidades contradictorias implicadas en el dominio técnico del puesto y en la consideración de las relaciones entre colegas, asumiendo inclusive tareas de encuadramiento. Cada uno debe saber negociar su trabajo, autoevaluarse, "venderse".

Una empresa de alta tecnología, así como todas las empresas de productos culturales editoriales, periódicos, cadena de televisión, grandes almacenes especializados en discos, libros o espectáculos, casa de alta costura, etc.-, aparece como un espacio donde la aptitud para teatralizar la presentación de sí es un triunfo esencial para el éxito de su carrera. En ese universo que recluta un personal joven, el cuerpo es un capital que debe ser conservado, desarrollado y mantenido. El mantenimiento del cuerpo "en forma" es un trabajo costoso, fatigante, un tipo de ascetismo al que nadie puede escapar. Pero todo indica que se trata de una aptitud que es distribuida de manera muy desigual, de acuerdo con el origen social o el sexo, en la medida en que el control de las expresiones corporales o de las emociones, que se aprende desde la primera infancia, es un indicio particularmente selectivo del origen de clase. Parece, sin embargo, que las mujeres de origen obrero consiguen apropiarse mejor de estas nuevas formas de "espíritu de la casa" que los hombres con la misma trayectoria social. Todo lo que recuerda los atributos de los obreros es rechazado por ser arcaico. Los obreros vestidos con overol de trabajo, que insultan a sus superiores - comportamiento frecuente en una empresa común-, ya no tiene lugar. Tales formas de lucha son

\footnotetext{
*Artículo publicado originalmente en Revista Actes de la recherche en sciences sociales $\mathrm{N}^{0} 114$, septiembre de 1996, pp 68-78. La presente traducción se apoya también en la versión portuguesa (realizada por Vanise Pereira Dresch y revisada por Julieta Beatriz Ramos Desaulniers), publicada en la revista Ventas, Vol.42, $\mathrm{N}^{0} 2$ (junio de 1997). Traducción de Martha Cecilia Herrera y Guillermo Bustamante Z. Profesores Universidad Pedagógica Nacional

"Profesor e investigador del Centre d 'Etudes de l'Emploi y de la Maison des Sciences de I 'Homme, París, Francia.

Profesora e investigadora del Centre d'Etudes de l'Emploi y del Collége de France, París, Francia.
} 
inmediatamente descalificadas, en un ambiente que es hecho justamente para eufemizar todo aquello que evoque situaciones conflictivas o vulgaridad.

Lo que se propone a los ejecutivos que se forman en la empresa, mediante la evaluación continua de los desempeños, se refiere más a principios de vida que involucran implícitamente el futuro de toda la familia, que a los aspectos relacionados con su carrera. En un período en que las posibilidades de promoción social están frenadas por la situación del mercado de trabajo, tales empresas pueden surgir como substitutas de la escuela. Es el caso de las actividades culturales, deportivas, en particular en días feriados y fines de semana, pero, sobre todo, de las actividades dirigidas a la sociabilidad, ligadas al ejercicio de la profesión: misiones y cargos en el exterior, posibilidades de vivienda en ciudades universitarias (ricas en dotación escolar o en posibilidades lingüísticas) que son también condiciones de acceso al estilo de vida y a los instrumentos de reproducción social de las capas medias.

\section{Trabajar en la urgencia}

En la empresa de informática observada [HP], las relaciones de trabajo aparentemente no son tensas. La preocupación por la "transparencia", obliga a cada uno de los asalariados a trabajar bajo la mirada de los otros, a pasar de los horarios libres a los horarios fijos, y, para una parte del personal, a trabajar en horario nocturno. Allí la evaluación constante de los desempeños, que no se limita a la evaluación anual o a la divulgación de los resultados obtenidos por cada equipo, son indicadores de las tensiones que la intensificación de la competencia suscita.

Esta filial de una multinacional instalada en Grenoble, a comienzos de los años setenta, fundada cerca de San Francisco en 1939, se caracteriza por una proporción de ejecutivos y de ingenieros sensiblemente más elevada que la de las otras empresas de la región, siendo la mayor parte del trabajo de producción subcontratada. Lo que parece definir los productos sofisticados, como aquellos de la informática, es el importante papel de la relación con la clientela, sobre todo en lo que concierne al mantenimiento, que lleva a unir estrechamente, en un mismo espacio, concepción, producción y comercialización de los productos ${ }^{1}$. Lo esencial del trabajo obrero (según un informe del departamento de personal, en 1990, los obreros representaban el $22 \%$ de los efectivos, contra el $44 \%$ de ingenieros y gerentes ${ }^{2}$ ) está consagrado al montaje y control de la calidad de los productos. Ampliamente mayoritarias $(81 \%)$, las mujeres son tan numerosas como los hombres en los empleos de obreros (50\%), pero ocupan solamente el $23 \%$ de los empleos reservados para ingenieros y gerentes.

En el sector de la informática, la renovación de los productos es constante e implica un ciclo de producción cada vez más corto, y la búsqueda de la innovación estimula una intensificación del ritmo de trabajo. En este mercado, que tiende a ser el ejemplo más exitoso de un mercado mundial, las búsquedas de la calidad y del beneficio están cada vez más estrechamente ligadas (retorno a la producción "en serie", trabajo nocturno, reducción de los horarios "flexibles", búsqueda constante en la baja de los costos de producción...). "Gerenciar

\footnotetext{
${ }_{2}^{1}$ Un segundo establecimiento, más centrado en la producción, fue creado después en la región de Lyon.

2 Informe de igualdad profesional entre los hombres y las mujeres del año fiscal 1990, Departamento de Personal, marzo de 1991. 
por objetivos" se apoya en la búsqueda de la calidad. Todo ocurre como si la autoridad estuviese diluida en todos los niveles del personal, incluyendo los subalternos: cada supervisor que, además, no tiene este cargo garantizado por toda la vida, es, a su vez, sometido a la autoridad de otro supervisor; de la misma manera, cada supervisado puede recurrir al supervisor de su supervisor.

Durante los años setenta, el crecimiento fue rápido: se pasó de una centena de asalariados a cerca de dos mil. Admitidos en su mayoría al inicio de la vida activa, los asalariados envejecen juntos. Los efectos de la edad son todavía más sentidos por estar acompañados por el abandono de la gestión "humanista", a la cual estaban muy ligados principalmente las mujeres-, los obreros reclutados dentro del personal dimitido de las empresas regionales de sectores en declive ${ }^{3}$ (textil, alimentación, etc.). En los años ochenta, obreros y funcionarios descubrieron colectivamente los problemas relacionados con la conformación y el envejecimiento de las familias: licencias de maternidad, ausentismo ligado a la atención de los niños de poca edad, divorcio. Como la mayoría de los grupos altamente escolarizados, es un personal que retardó el calendario de los nacimientos: la mayoría de las mujeres tuvo su primer hijo después de los treinta años. Si todos los asalariados comenzaran su carrera profesional solteros, el sentido que se debe dar a esta forma de celibato provisional es diferente para los hombres que para las mujeres, las cuales probablemente no habrían sido contratadas si fuesen madres de niños pequeños.

Lo que nos interesó en esta investigación se refiere, menos a un estudio preciso de los cargos, que a las trayectorias de asalariados, definidas por un conjunto de variables que no aparecen en las categorías de las estadísticas del mercado de trabajo. En primer lugar, la mayor parte del personal no es de la región. Reclutados en un mercado nacional e, incluso, internacional - gracias a los lazos estrechos de la empresa con el mundo escolar ${ }^{4}$ - los asalariados tienen pocos vínculos de familia o de amistad con la población local. En segundo lugar, aunque una parte de ellos ocupe puestos que exigen mayores niveles académicos de los que poseen, están lejos de ser autodidactas, de acuerdo con la idea que se tiene habitualmente de los ejecutivos que se forman en la empresa. Al contrario, aquellos que tuvimos la ocasión de contactar tenían buena formación escolar, inclusive de nivel superior. Los responsables del reclutamiento insisten en la importancia que atribuyen a las competencias escolares que permiten "evolucionar" (el "potencial"), mucho más que a los diplomas. En fin, han desempeñado un papel importante, para cada uno de ellos: las características "individuales" asociadas a los compromisos cívicos y las inversiones culturales, asociativas o religiosas, así como un buen conocimiento del inglés hablado.

\section{La empresa vista a través de la enfermería}

El espíritu de la empresa es visible apenas se entra en el establecimiento: la voz, la postura son "trabajadas", como si cualquier relajamiento corporal fuese el signo de un relajamiento

\footnotetext{
${ }^{3}$ El caso más conocido es el de los obreros de los establecimientos Lou, donde el personal dimitido ocupa la empresa por varios meses. Sobre este tema, cf. Pierre Frappat, Le Mythe blessé. Grenoble: Arthaud, 1979.

${ }^{4}$ Sobre los lazos establecidos por la empresa con los establecimientos escolares de Grenoble, principalmente a través de propuestas de pasantías. préstamo de material informático, convenios de colaboración, etc., cf. Gabrielle Balazs y Jean-Pierre Faguer, Cahier 32 du Centre d'etudes de l'emploi, París: PUF, 1989, cap.III. "La política local de las relaciones entre la escuela y las empresas".
} 
moral. En la recepción, el tono es dado por los altoparlantes, cuyos mensajes, en inglés y en francés, evocan las voces de los aeropuertos. Las telefonistas son, al mismo tiempo, recepcionistas y reciben los visitantes -clientes, abastecedores, representantes comerciales, funcionarios de otras empresas, etc.--; anotan sus nombres, el de la compañía que representan, la hora de llegada, y les dan una escarapela. Así, los controles se operan, de manera discreta. Para ellas, lo esencial está en la postura y en la eficacia (a pesar de numerosas llamadas telefónicas, del gran número de visitantes y del paso rápido de la lengua francesa a la inglesa, nunca se debe correr o elevar el tono). El trabajo y el esfuerzo no deben ser percibidos por los que vienen de afuera. No se debe dar señales de irritación o de cansancio. La organización del espacio (arreglos florales, exposición de productos en vitrinas, salas de recepción con algunas obras de arte) y el modo de actuar del personal con los visitantes hacen sentir, desde la entrada, que se está en un universo distante no sólo de aquel de la empresa industrial tradicional, sino también de aquel de la función pública. Incluso entre colegas, la informalidad no debe transformarse en familiaridad. Es preciso saber mantener la distancia, lo que un ambiente de alta tecnología (correo electrónico, computador en cada oficina, etc.) facilita.

Como señala una de las funcionarias:

No se puede ser excepcional trescientos sesenta y cinco días por año. Observen que las evaluaciones de los desempeños llegaron, inclusive, a encuadrarnos: uno es "aceptable", "bueno" o "muy bueno", llegando hasta el último nivel donde las personas son "excepcionales". Yo les dije: "esperen ahí, jesto es un juego! Excepcional, la gente es excepcional de cuando en cuando" [...] Yo ni sé: en un restaurante, un día usted le dice al chef: "¡Ah!, ¡tu comida estaba excepcional hoy!”, porque, bueno, él tuvo un día, aquel día, fue la genialidad del día. Yo digo: "excepcional trescientos sesenta y cinco días por año, no es aceptable, no es posible, por tanto no debería haber nadie!". Y, sin embargo, hay personas que están en el nivel del excepcional.

Las tensiones pueden ser más fuertes cuando se trabaja en un ambiente joven, deportivo, donde la competencia profesional es inseparable del culto al cuerpo ${ }^{5}$. Un conjunto de actividades son propuestas en el horario del almuerzo o durante los fines de semana y los días de fiesta: stretching, escaladas, tenis (una pared para escalar y canchas de tenis fueron construidas en la fábrica), y el personal, inclusive los obreros, cuidan de su forma física, dedicándose a actividades deportivas, consideradas como actividades de "formación permanente", entre otras. El trabajo con el cuerpo tiene también una dimensión moral: el esfuerzo para dominarlo, el control de las emociones son expresiones del proyecto de ascenso social. El vestuario, generalmente práctico, la postura física, las actitudes informales se refieren a exigencias de salud, de gusto por la naturaleza y por el placer sano, que están en afinidad con la representación, en las imágenes publicitarias, del cuerpo de los ejecutivos.

La enfermería es uno de los únicos lugares donde los asalariados pueden substraerse, por un momento, a la presión que es ejercida sobre ellos y dejar provisionalmente de fiscalizarse. "En una oficina, usted está con dos o tres, usted se des-ahoga con dos o tres; si su producción cae o si comienza a gritar porque tiene una crisis de nervios, el edificio entero para y mira: surgen cabezas por encima de las divisiones y dicen: “¡Ey!, ¿qué está

\footnotetext{
${ }^{5}$ Las publicidades recientes que han aparecido en la prensa para contratar ingenieros y técnicos insisten en el ambiente "californiano" y en los valores de los "años 60 " de la empresa. 
pasando?". No se debe olvidar que las tensiones son todavía más fuertes porque el mercado de trabajo, incluso en la electrónica, se ha vuelto progresivamente más selectivo. Los asalariados han interiorizado el miedo al desempleo por ver a su alrededor, cada vez más, trabajadores interinos o con contrato temporal, mientras un número cada vez más significativo de tareas es confiado a empresas externas.

Los signos clínicos, diagnosticados por el personal médico, son numerosos: el ausentismo y las interrupciones de trabajo, que provienen sobre todo de las mujeres, desde que los horarios pasaron a ser fijos; los asalariados que vienen a "explotar" en la enfermería; el "desgaste de los ejecutivos" que amenaza, en verdad, a todos los asalariados; en fin, las depresiones y las enfermedades prolongadas.

De acuerdo con una de las enfermeras, los empleados recurren mucho a licencias de salud, "por depresión", "la lista de medicinas a ser tomadas está compuesta de antidepresivos", y "hay un malestar general":

A partir del momento en que usted no está bien, el problema es para la empresa; es preciso tener, al menos, una base familiar o una vida personal sólida. Si, por acaso, se peca un poco por este lado, generalmente la gente ve las personas decaer algún tiempo después, en el trabajo. No funciona más porque, efectivamente, sufren mucha presión en su trabajo; sí no tuvieran una compensación afuera o algo que las renovara, que les hiciera bien, sería el fin, el desmoronamiento [...] no hay ninguna estructura (para atenderlos), oficialmente, eso no existe. En contrapartida, entonces, se ve con mucha frecuencia a los supervisores asumir directamente la responsabilidad de las cosas y, entonces, nosotros, los del servicio médico, damos saltos cuando ellos vienen a contamos ciertas cosas [...], no sé, personas que comienzan a asumir prácticamente el divorcio de uno de sus funcionarios.

[...] Hay ejecutivos que vienen de París, por ejemplo, $\mathrm{X}$, miren en qué estado lo dejaron. Competitivo hasta la jubilación, infarto en el aeropuerto de Washington, y todavía está ahí, trabaja medio turno, pero creo que es alguien que realmente da su vida hasta el fin por la HP. Es el antiguo director de... Ahora él trabaja con moderación. Yo diría que él da su vida, con parsimonia ahora, o sea, su incidente hizo que dijera: "¡Ah, ya no más! Casi me muero, no continúo más" y en 48 horas, pidió su dimisión de la alta dirección y les dijo: "Encuéntrenme otra cosa, no quiero morir en un avión!".

La enfermera - cuya entrevista se transcribió en parte- está, al mismo tiempo, dentro y fuera de la empresa (es una asalariada entre otras, sometida a los mismos horarios, al mismo ambiente de trabajo, a los mismos criterios de evaluación); esta posición, así como su trayectoria, le permiten tener una visión un poco distante, lo cual hace de ella una informante sensible a los efectos patológicos de un espíritu "doméstico", al cual no puede totalmente adherir. Hija de un antiguo obrero que se volvió ejecutivo en una importante empresa local, casada con un ingeniero, madre de un niño, ella ingresó, después de diversas experiencias profesionales —entre ellas 5 años en la región parisiense-, con la esperanza de encontrar finalmente condiciones de trabajo más compatibles con su vida familiar ("yo tenía buenas propuestas, principalmente la de la prisión de la Santé"). Sus primeros empleos son "estresantes": un puesto nocturno en servicio de reanimación, un trabajo con personas de la cuarta edad, un reemplazo como enfermera en una cantera. Representante del personal, esta mujer, que hace teatro durante sus horas libres, tiene, sin embargo, un punto de vista 
sobre la empresa que se debe a la posición que ocupa en los únicos bastidores de un lugar de trabajo donde la presentación de sí hace parte de la definición "pragmática" (aquella que no se encuentra en los reglamentos internos, ni en la descripción de los "perfiles de cargos") de la competencia profesional.

Si recibimos, en verdad, tanta gente en la enfermería, es por ser uno de los escasos lugares cerrados. Una vez vi, en el departamento de personal, a alguien recibir una llamada telefónica: su abuela, muy enferma; e inmediatamente comenzó a tener los ojos llenos de lágrimas. Había veinte personas alrededor y todos pararon de hablar; no lo hicieron por mal, yo diría que eso hace parte del ser humano: usted siente que alguien recibió una llamada no muy buena, las cosas no van bien... Conclusión: usted no se desata en sollozos en el teléfono, sino que se abstiene, se inhibe hasta de pasar por la puerta de la enfermería. Después, es allá donde explota, porque se necesita de eso de vez en cuando [...].

Tenemos un pequeño sistema en la enfermería que vale por lo que es, porque, como estamos en un equipo y no podemos proponer grandes cosas a las personas, cuando vemos que ellas están paralizadas, después de tres semanas, un mes, les enviamos una canica, en la cual escribimos: "Bueno, escuche, usted está parado desde el día tal..., si necesita, nos gustaría mucho tener noticias suyas; si necesita, entre en contacto". La enfermera que yo sustituí le hubiese gustado haber llegado a tener el estatus de asistente social; ella hacía la parte social, atendía las personas, era alguien que tenía un dinamismo fantástico. Telefoneaba a las personas, hacía esto porque era antigua en la empresa y porque, finalmente, conocía a casi todo el mundo. Cuando ella entró, eran unos cien; por lo tanto, era una pequeña familia. Yo llegué, ella me dijo: "Tú entiendes, algunas veces llamo, me fue mal una o dos veces, tuve personas que me dijeron: 'j,Qué pasa?, ¿por qué el servicio médico?, ¿usted está verificando que estoy muy enfermo?'. Y esto puede ser vivido así, como un control". Entonces, ahora decidimos hacer una cartica con dos o tres frases: "si quieres, llama, si no quieres...".

-¿Y después?, ¿si eso continúa?

- En la mayoría de los casos, las personas nos llaman diciendo: "Estoy realmente muy contenta, tengo la impresión de que alguien... ustedes no me están olvidando completamente". Por desgracia, el problema es que no podemos hacer más que eso. Yo me planteo la cuestión: un día, nos va a suceder que la persona nos va a llamar diciendo: "¡Sí, tengo un gran problema, vengan a verme!". Y no se cómo vamos a hacer.

- Usted decía que tenía relaciones privilegiadas con los médicos de la ciudad, ¿qué tipo de médicos?, ¿psiquiatras, clínicos generales?

- Al comienzo, yo los enviaba... Primero, en Francia, el psiquiatra es, pese a todo, mal visto. Decirle a alguien: "Oye, deberías ir a ver un psiquiatra, eso te haría bien" generalmente, es un poco... Intentamos enviarle a médicos generales que disponen de tiempo. Un buen médico general que dispone de una hora para intentar comprender un poquito, bueno, ya es un verdadero paso, y tal vez, en su consultorio, a través de él, las personas lograron mejorar. $Y$ segundo, es verdad también que los psiquiatras... yo 
conocía algunos a través del servicio de reclutamiento, porque su personal estudió psicología inicialmente; por tanto, ellos tienen conocimientos en esta área. Es verdad que conocen personas ciertamente buenas, que ayudan, pero son excesivamente caras y para alguien que trabaja, por ejemplo, en la producción, yo diría que es casi imposible, si le cuesta 600 francos por semana [...]. En muchos casos, es un detalle que no va muy bien en un momento, que requeriría apenas un empujoncito y de alguien que le aclare un poco el problema, que lo viera desde afuera y que le dijese: "Oiga, bueno, tal vez sean esta y aquella las cosas sobre las cuales debe trabajar", pero después, esas personas, psicoterapeutas, resulta que no son reconocidas. por la seguridad social; es un problema...

- ¿Nunca le sucedió recurrir a un servicio de urgencia psiquiátrica?, ¿personas que realmente se desmoronan?

- Sí, dos veces [...] No era un servicio de urgencia psiquiátrica, llamamos al Servicio de Atención Médica de Urgencia [SAMU]. Una vez —mi colega de la noche atendió eso-, alguien estaba muy deprimido; de acuerdo con la teoría actual, si alguien está así, hay que intentar hacerlo volver al trabajo, porque se sabe muy bien que, en casa, las personas andan en círculos y no consiguen salir de eso. Era alguien que estaba bajo un tratamiento muy fuerte, tuvo que duplicar sus medicinas porque no estaba bien y tenía que soportar nuevamente, la presión de la HP, que a pesar de todo, esta ahí. Llegó a la enfermería en un estado... estaba casi delirando; como no hay servicio de urgencia psiquiátrica en Grenoble, tenemos que transferir todo para El "42-42-42" el SAMU. Ellos están bien preparados para este tipo de cosas [...]. El otro caso fue el de una chica de la cafetería que también estaba tomando medicinas; debía tomar medio comprimido, creo, por día, pero se había tomado seis. Ella no representaba realmente un problema para nosotros, pues dormía. Sin embargo, jno podíamos dejarla dormir todo el día en la enfermería, controlándola cada quince minutos!, eso nos parecía bastante pesado.

\section{Control y complicidad}

La confianza constituye uno de los componentes de la cualificación profesional de un personal intermedio cuya función esencial consiste en establecer el vínculo, en "comunicar". Toda transmisión de información, así sea personal, "hacia afuera" puede tener consecuencias sobre la imagen de la empresa; puede ser entendida como comportamiento inadmisible; aunque no esté mencionado en el reglamento interno, corre el riesgo de ser asimilada, en muchos sentidos, a una falla profesional. Así, para esta encuesta, los asalariados responderían bajo la condición de que su supervisor, o un miembro de la dirección, fuese informado previamente de los objetivos de la investigación y les diese autorización para participar. Las vacilaciones y los numerosos rechazos a las entrevistas contrastaban con el tono aparentemente libre que existe entre la jerarquía y el personal: presencia de ejecutivos de alto nivel en los mismos edificios, empleados separados en salas de vidrio que exponen a cada uno a trabajar bajo la mirada de los colegas y de los jefes, "tuteo", rituales de integración (como el "intervalo para el croissant" en la mañana, las bebidas para celebrar los éxitos de un equipo cuando un objetivo es alcanzado), libertad de circulación dentro de los edificios o de reunión. 
Los responsables de la comunicación controlan, tanto las informaciones relacionadas con los productos y su fabricación, como aquellas ligadas a las relaciones del personal y a la imagen de la empresa que puede ser, a través de ellos, vehiculada hacia el exterior. Mientras una cita había sido establecida desde París con una secretaria, durante las horas de trabajo, ella llegó a la recepción acompañada por el director de comunicación, quien vino a informarse de nuestros objetivos, con el propósito de revertir deliberadamente la situación de investigación.

Sería necesario describir, al mismo tiempo, los rituales de integración y los sistemas de auto-evaluación aplicados por supervisores -más próximos a consejeros psicológicos que a capataces-, el abanico de las técnicas sociales de encuadre que conducen a invertir excesivamente en los asalariados. Este modelo de gerencia está a tal punto interiorizado que perdura, a pesar de las transformaciones recientes del trabajo que se volvió más directivo ${ }^{6}$ para el personal obrero, por causa de la crisis (recurso al trabajo nocturno, incluso para las mujeres, y un modo de trabajo tayloriano para líneas de producción).

Los principios de evaluación a los subordinados son comunes para todos los supervisores, pero la percepción de los problemas, los límites de intervención varían, por lo que parece, de acuerdo con la manera como ellos "escalaron" en la empresa. Dos recorridos nos parecen ejemplares de este proceso de vinculación con la empresa y de adhesión a su modo de gestión. Dos supervisores, ambos de las capas medias, tienen, no obstante, una experiencia diferente, "en lo masculino y en lo femenino", del ejercicio de la autoridad. El hombre tiene un baccalauréat $^{7}$ en literatura, obtenido en una reputada escuela de enseñanza privada de la región parisiense (nos había sido presentado como un ejemplo positivo de diplomado en literatura, capaz de conseguir su reconversión en una empresa cuyo capital profesional es de base científica); él piensa que su función implica, en cualquier ocasión, mantener distancia de sus subordinados:

Si el desempeño cae, creo que lo que debemos hacer es constatar que efectivamente está cayendo. Las personas comienzan a cometer equivocaciones, están distraídas, creo que es preciso hacer que comprendan que estamos viendo que, efectivamente, hay una caída en el desempeño, que eso no es aceptable, no es normal; eso me sucedió, hace seis u ocho meses, con una funcionaria, yo le dije: "Escucha, OK", ella me habló de su problema, yo sabía lo que pasaba y le dije: "OK, su desempeño no está bien; pero no voy a tenerlo en cuenta para esta evaluación, olvido estos tres meses, pero, mientras tanto, es preciso que esto se resuelva rápidamente, porque no podrá durar eternamente como está" [...]; tenemos, tal vez, tendencia a cierta piedad, y esto no funciona, es realmente un desastre [...]. De ninguna forma debemos involucramos con los problemas personales, porque es un fracaso garantizado.

La mujer entrevistada — hija de pequeños comerciantes de la región, admitida a los 18 años como operadora en la producción, con apenas un $\mathrm{CAP}^{8}$ de establecimiento de enseñanza

\footnotetext{
${ }^{6}$ Un acuerdo sobre la reducción del tiempo de trabajo, para compensar el paso al trabajo nocturno y garantizar la contratación de desempleados fue firmado, en 1992, por los sindicatos y promovido por el Estado (el primer ministro se movilizó para reforzar el aspecto ejemplar de este acuerdo).

${ }^{7}$ En Francia, el primero de los grados universitarios que otorga un diploma que acredita el fin de los estudios secundarios. Suele decírsele "bac".

${ }^{8}$ Certificado de Aptitud Profesional, formación técnica al nivel de enseñanza secundaria [nota de la edición en portugués]. 
pública- se volvió supervisora después de haber sido asistente técnica. En su caso, se esfuerza por ejercer su autoridad dentro de la cercanía y la complicidad. Antigua auxiliar de enfermería, después obrera en una industria de alimentación, comparte la misma historia profesional de las mujeres que supervisa, para las cuales esa empresa del sector electrónico representó una mejoría sensible del salario, de las condiciones de trabajo, de las perspectivas de futuro: "Vi la diferencia cuando entré aquí; allá lo importante era la línea de producción, no se tenia contacto, como se tiene con nuestros supervisores o supervisados [...]. La diferencia de trabajo cambió las vidas de las personas de la 'Lou', de la 'Valisére"'. Cita el caso de sus hermanos, jefe de bodega y jefe de grupo en dos empresas de los suburbios: "comparando mi antigüedad y la de ellos, ellos dicen que realmente se tiene suerte de trabajar en la HP".

Su estatus de madre soltera está bien aceptado, le propusieron el cargo de supervisora al regresar de su licencia de maternidad: "No sé si es porque yo era soltera y por lo tanto disponible, o qué". Mantiene lazos personales con sus subordinados, fuera del horario de trabajo: "Tengo contactos externos con mi personal, viajes, salidas, nos invitamos para ir a casa, una vez por año, reunimos a todo el mundo, tanto supervisores como supervisados, y salimos juntos a comer". En su trabajo, ella sabe anular el carácter dramático del procedimiento de evaluación de los desempeños, que es en sí fuente de tensiones ("utilizo un formulario estándar para todo el mundo") y, al mismo tiempo, orientar a los asalariados que tienen problemas: hacia la enfermería, hacia el departamento de personal 0 , eventualmente, hacia un abogado.

\section{Los usos caseros de los diplomas}

Los principios de responsabilidad, autonomía en el trabajo y control de sí, son también maneras de reconocer la legitimidad de los diplomas, sin reconocer el título que confieren. En el caso de los asalariados de origen popular, la trayectoria garantiza, por sí sola, la presencia de las cualidades tradicionalmente vinculadas con la mano de obra femenina (dedicación, apego al trabajo, modestia, minuciosidad, olvido de sí). La presencia de un personal "sobretitulado" es verificada incluso en el caso de las mujeres que ocupan puestos de producción. Se puede citar, por ejemplo, una hija de agricultores provenientes de una familia católica de muchos hijos, titular de una especialización en Letras, obtenida como becaria en una escuela de enseñanza privada (ella tenía que hacer limpiezas y tareas manuales para pagar su escolaridad), admitida como obrera desde los primeros meses de abierta la fábrica. Separada de su marido y con dos hijos pequeños a su cargo, después de un año de desempleo fue contratada sin haber dicho que había hecho la especialización e iniciado los estudios de asistente social para tener más posibilidades de obtener un empleo en el nivel de brevet $^{9}$. Después de 17 años en la producción, gracias a la formación permanente, ella ascendió a un puesto de telefonista bilingüe.

El esfuerzo exigido es todavía mayor para los funcionarios y técnicos a partir del momento en que su capacidad fue reconocida y que fueron colocados en competencia con los ejecutivos. Así, una antigua técnica sin título (entró en la HP antes de haber obtenido un BTS [una prueba], para el cual no llega ni siquiera a pasar la prueba oral), fue encargada, después de una pasantía en los Estados Unidos, de enseñar a ingenieros el modo de

\footnotetext{
${ }^{9}$ En Francia, diploma o certificado que acredita una formación en nivel secundario de obrero o funcionario calificado o técnico [nota de la traducción al portugués].

Digitalizado por RED ACADEMICA
} 
utilización de un producto del cual ella es una de las únicas especialistas en esta multinacional. Confrontada con hombres seguros de sí ("personas que son formadas no sólo en la técnica sino también en el estado de espíritu, enseñadas a decir 'soy bueno, soy el mejor"'), con personal del área comercial, con un público internacional al cual ella se dirige en inglés, muchas veces más atento a las innovaciones ligadas a este producto, su autoridad es constantemente cuestionada: una falta de legitimidad escolar ("yo podría haber hecho preparatoria" 10"), social (es hija de un chofer de bus que también se volvió instructor) e "identitaria" (una mujer soltera en una carrera de hombres) hace que ella viva su situación como imposible.

Encontraron que yo era muy pedagoga; mis colegas, me decían: "deberías presentarte como instructora”. Entonces, fui allá y me aceptaron. En verdad, ellos no deberían haberme aceptado, porque el departamento de personal estaba en contra. Pero, a pesar de eso, fui admitida en el sector de entrenamiento y, con el pasar del tiempo, me estoy dando cuenta de que el departamento de personal tenía razón: yo me adapté muy, muy mal, fue muy difícil para mí allá. Fue casi la misma historia del bac; yo no tengo confianza en mí, pues cuando usted está delante de dos personas para formarlas, es preciso estar seguro, y este no era mi caso; por lo tanto, no viví bien la situación. Fui admitida y rápidamente fui a los Estados Unidos a formarme. El curso no es como la escuela, es peor. Usted tiene un grupo, tiene 6 máquinas y 12 personas. De hecho, como teníamos dificultad en responder a la demanda, teníamos muchas veces 14, 16 personas. Los cursos que yo daba, jduraban 5 semanas! Yo pasaba, por lo tanto, 5 semanas sola en mi salón, con mis 14 muchachos, porque eran sólo hombres -yo había sido admitida, pero era la primera mujer que ellos admitían y, en Europa, yo era la única - [...]. La clase se dividía siempre en dos partes: en la mañana, teoría, y en la tarde, lo que se llama los "laboratorios", que son trabajos prácticos; en la mañana, se explicaba el funcionamiento de la máquina: todos nuestros salones de clase tienen un retroproyector, y proyectamos transparencias; era yo quien creaba el curso, era yo quien escribía. Preparar una clase era una locura: yo estaba siempre atrasada, entraba en pánico. ¡Son 5 semanas, 8 horas por día; en la noche, usted prepara entonces su material para el día siguiente! Al cabo de 5 semanas, yo simplemente jestaba enferma! Estaba muerta, no resistía más... Porque, para hacer este trabajo, las personas que lo hacen bien no se preocupan por nada, finalmente, tienen cierto desprendimiento, una cierta facultad de desprenderse de aquello que está sucediendo, no se...

En pedagogía, yo no era mala, no era un problema de pedagogía el que yo tenía. No; cuando yo explicaba alguna cosa, los muchachos comprendían bien... ¡cuando yo sabía! [risas]. ¡Cuando yo no sabía, las cosas no iban bien! Los otros colegas tampoco sabían, pero ellos no prestaban atención a eso, decían: "Oh, eso usted no tiene necesidad de saberlo", mientras yo hacía una cantidad de trucos de las cosas que no sabía. Era necesario enseñar 25 semanas [...]. No soporté muy bien, en el primer año, era horrible, entonces, en el segundo año, estaba empezando a buscar otra cosa para hacer, porque sentía que iba completamente... Durante el curso, era horrible: por la mañana, llegaba, iba a llorar al baño, y después, como era la hora de ir a la clase, iyo iba! ¡Era horrible!, yo tomaba medicinas, en resumen, no aguantaba más. Contrataron otra chica para el curso, y ella venía de una escuela de ingeniería, era ingeniera. La pusieron a trabajar conmigo justamente: estábamos encargadas de los mismos

\footnotetext{
${ }^{10}$ Clase de preparación para acceso a las grandes escuelas. 
productos, de los mismos cursos, yo tenía que formarla. Al cabo de 6 meses, se retiró. Al igual que yo, no aguantaba más: ¡rabiaba todo el tiempo! [risas]. ¡Era verdaderamente el dúo infernal!

Otro ejemplo, tomado de las secretarias: la asistente de un director de departamento que tiene todos los atributos de una persona que ocupa un cargo de confianza, cargo cuya función depende, en parte, de la carrera del responsable para quien ella trabaja. Se trata menos de realizar tareas técnicas que de ejercer con discreción un trabajo de comunicación, esencialmente en inglés (teléfono, correo electrónico), administrar la agenda de un gerente que viaja mucho ("es una cosa difícil cuando se tiene un jefe brillante, pero que es completamente desorganizado"), preparar reuniones con todo el equipo, remplazar al jefe durante su ausencia. Un largo período de desempleo, la experiencia de pequeños empleos (entrevistadora para un gran centro comercial, trabajos temporales para un estudio europeo en un organismo internacional, traducción asistida por computador) y su trayectoria familiar de hija de obrero, con una maestría en lenguas (obtenida con 4 años de estudios superiores), seguida de un año en Inglaterra y con un Diploma de Estudios Superiores Especializados (obtenido con un año adicional de estudios - DESS) en economía del trabajo, explican que ella haya aceptado ingresar en la HP como secretaria interna, de nivel "bac", esperando el reconocimiento posterior de sus títulos.

Permanecí casi un año y medio desempleada [...] cada vez que me presentaba para un puesto, lo que no encajaba era mi formación. Pasaba por todas las etapas, tenía varias entrevistas y, en la última etapa, siempre se presentaba un obstáculo, siempre era la formación. Me saturé y me inscribí en $\mathrm{Ecco}^{11}$, y después llegué un día a la HP así[...]. Un mes después, el contrato terminó y, en el intervalo, yo continuaba mis búsquedas; entonces, más o menos seis meses después, volvieron a entrar en contacto conmigo, diciendo: "Vea, hay una vacante de secretaria, sé que les gustaría mucho que usted la tomase; entonces, venga a ver". Fue así, sin pasar por el departamento de personal; era uno de los dos jefes para quien iba a trabajar el que quería que fuese yo [...]; todo estuvo bien, él dio el OK. Bueno, yo me dije: "Finalmente, resultó, qué maravilla". Y después, para mayor seguridad, pasé mi hoja de vida al departamento de personal, sin haber dicho que tenía un DESS. Y fue allá, me acuerdo muy bien, que la responsable del departamento de personal me dijo: "Para mí, no está fuera de duda que usted sea contratada", y entonces pasé después al sector de marketing, fui a verlos y les dije: "Bueno, lo siento mucho, pero no está bien". En seguida, tuve toda una fase de negociación, yo estaba sin trabajo. Y entonces, en el dossier, estaba bien señalado: "Me forzaron, yo contraté". Yo hasta comprendo la idea de ellos de emplear personas que van a progresar después; entonces, ella me dijo: "Estoy absolutamente segura de que, cuando usted esté aquí, lo hará, pero con relación a su formación, tarde o temprano, usted estará frustrada". Y fue más o menos lo que pasó después. Yo era entonces la secretaria de dos departamentos, y es verdad que, dos años después, yo ya había experimentado todo en el trabajo y estaba realmente frustrada.

\section{El "fuera del trabajo" en el trabajo}

Para el médico laboral empleado por el establecimiento, la "filosofía" de la empresa se resume en la "idea de promover las personas y hacer que puedan administrar su vida

\footnotetext{
${ }^{11}$ Empresa de trabajos temporales [nota de la traducción al portugués]. 
personal. Es una idea muy personalista, excelente. Aquí no se desea y no se quiere ser asistencialista. Es preciso admitirlo, cada uno debe encontrar su lugar en un sistema que está formalizado en ciertos aspectos y que, en otros, es perfectamente informal.

Aquel que no encuentra su lugar, tiene dificultades". De hecho, el estrés fue varias veces evocado por los entrevistados que lo relacionan con la ausencia de "planeamiento de los cargos". Cada uno es llevado insensiblemente a mezclar trabajo y "fuera del trabajo", a equipar su domicilio como un anexo de su escritorio (teléfono, fax, computador portátil, impresora $^{12}$, pero sobre todo, a causa de las incertidumbres de la vida profesional, a someter la vida familiar y el tiempo libre a los imperativos del cargo. En el siguiente pasaje, una joven líder sindical, ingeniera de investigación, de una familia de funcionarios públicos parisienses y que hizo gran parte de sus estudios en el exterior, evidencia cómo esa incertidumbre y esa evaluación permanentes pueden producir un distanciamiento del personal que envejece ("el desgaste de los ejecutivos"), una dificultad, para las mujeres, de ocuparse de su familia, y puede constituir, finalmente, un obstáculo a una afiliación política o sindical.

Después de cierto tiempo, es verdad que hay algunos ejecutivos que tienen más de 50 años. Son personas que no pueden reconvertirse; entonces hoy, no tienen las competencias que HP necesita. Parece que ya hubo un caso de out-placement ${ }^{13}$. Hay casos de personas que no tienen nada que hacer, que fueron echadas de su tarea actual por ser consideradas no competentes, y la gente se pregunta... Se tiene la impresión de que, para hacer alguna cosa, esperan a que la persona se desmorone. Esto no está bien administrado y el problema es que todo el personal administrativo debe razonar en corto tiempo, porque tiene objetivos a corto plazo, ellos están saturados por los negocios [...]. Era incluso una especie de reivindicación de parte de la HP decir: "No administramos las carreras porque no es necesario". No hay ningún problema de recolocación para nuestros ejecutivos. Era algo que se decía alto y fuerte. Hoy, ellos comienzan a darse cuenta de que sería necesario, tal vez, que fuesen capaces de tener planes para la carrera de las personas. Nadie tiene plan para la carrera. Y cuando usted lo pide... eso me sucedió: yo me dije: "debe haber especialistas, en algún lugar, que me puedan ayudar a saber lo que quiero hacer de mi carrera; no es problema del departamento de personal". Le correspondía al supervisor suministrar la asistencia... (y para las mujeres), es preciso ser una wonderwoman, con hijos dejados un poco a su libre albedrío, etc. (esto sucede a menudo en los Estados Unidos), para tener efectivamente una carrera, progresar; creo que la elección es real, no quiero fingir que no veo esto; es una deficiencia y es difícil justamente con toda esta cultura de sesenta horas y este peso que se siente cuando no se da el máximo de sí a la HP; estamos en un contexto psicológico muy difícil de soportar y creo que, personalmente, es necesario tomar una opción: o no dedicar el tiempo que se debería a la familia, o entonces es necesario saber que su carrera sufrirá las consecuencias...

\footnotetext{
${ }^{12}$ En un reportaje presentado a comienzos de 1996, por la M6 (televisión) en el programa "Capital", vimos, por ejemplo, un ejecutivo del área comercial de esta empresa obligado a trabajar en la casa desde la supresión de varias agencias comerciales en provincia. Él instaló su oficina en una pieza separada del resto de su apartamento por una división y, cuando estaba trabajando, usaba vestido de paño y corbata.

${ }^{13}$ Término en inglés, consagrado en el lenguaje empresarial francés, que designa el esfuerzo de las empresas en resituar en el mercado de trabajo los empleados que no pueden ser mantenidos en la empresa [nota de la traducción al portugués]. 
Es una forma de renuncia, cuando yo esté delante de una familia, mi carrera quedará, yo misma, mi carrera quedará atrás, esto cortará mi carrera. Mantendré una actividad profesional, sea como sea, por muchas razones, en caso de situación difícil, porque creo que la independencia de las mujeres es algo... Soy muy sensible a esto y siempre quiero mantener los medios de ser independiente en caso de situaciones difíciles y, para esto, es indispensable mantener un pie en la industria, si nos descuidamos en este contexto... Si se deja, entonces, de trabajar tres años, se está acabado. En tres años, la gente queda completamente desactualizada en el plano de las competencias, parar tres años significa no tener trabajo después.

Las personas tienen mucho miedo de arriesgarse en acciones del tipo representar al personal, porque todo es individualizado: la fijación de objetivos, la evolución de la carrera, la evaluación del desempeño, el aumento salarial, y todo es extremadamente dependiente. Acabo de sufrir esto porque yo tenía malas relaciones con mi supervisor [...]. Fui candidata en las elecciones municipales, tan pronto volví de la licencia, allá para las elecciones locales, por supuesto que yo no estaba en un estado físico y nervioso brillante, y me involucré en la campaña de las elecciones municipales, y mi supervisor cambió completamente su comportamiento: estaba imposible, yo ya no era confiable para él, no era posible [...] yo trabajaba cuatro días en vez de cinco y eso quería decir claramente treinta horas, yo realmente no hacía horas extras, no era posible y, para él, treinta horas era medio turno, no llegaba a cuatro quintos, porque un ejecutivo trabaja sesenta horas, un ejecutivo está sujeto a todo. Yo era alguien que huía a las cinco de la tarde para ejercer "mi segunda vida", como él decía...

Cuando las mujeres tienen responsabilidades profesionales, las presiones del celibato prolongado o del embarazo postergado, así como las tensiones que todos los asalariados sienten entre su vida privada y las exigencias de disponibilidad por fuera del horario de trabajo, son particularmente ilustradas por las parejas formadas entre asalariados (HP es presentada, con humor, como la "mayor agencia matrimonial de Grenoble"), que comparten los mismos gustos, así sea por el hecho de haber sido seleccionados según los mismos criterios de formación y de expectativa de movilidad social.

Podemos apoyarnos en el ejemplo de esta pareja, secretaria y técnico, provenientes de familias obreras española e italiana. Habiendo decidido continuar trabajando de tiempo completo, después del nacimiento de su segundo hijo, la mujer es, desde su regreso, asistente de dirección, "un papel de soporte administrativo para uno de los gerentes y todo su staff', un trabajo que cambió completamente su óptica profesional: "A través de este puesto, tuve la oportunidad, es verdaderamente una oportunidad, de ver el conjunto de la organización, del comienzo al fin, partiendo de la locomotora hasta el último vagón".

Al contrario del empleo de su marido (reclutado dos o tres años después de ella para el área de compras, con un diploma de diseñador industrial, un área donde el tránsito a ejecutivo está "más o menos trazado"), el interés de su trabajo depende de la diversidad de las tareas y de su disponibilidad:

En el cargo que ocupo, hay muchas cosas que, tal vez, no están escritas en blanco y negro, pero que son hechas por la persona que lo ocupa. Es típicamente este género de función, las funciones de secretaría, las pocas funciones de HP que se vuelven aquello que la persona quiera hacer de ellas. Es extraordinario. Si yo quisiera tener un 
trabajo rutinario, podría muy bien ocupar este mismo cargo, en el mismo lugar, y hacer ese tipo de trabajo. La rutina, confieso que huyo de eso. Ser dirigida en aquello que hago, tampoco me gusta mucho. Lo que me gusta es tener mi trabajo y organizarme como quiero para hacerlo y también intentar traer cosas nuevas; esto corresponde exactamente a lo que busco. No tengo ningún propósito de volverme ejecutiva. Actualmente, no veo en qué me aportaría eso.

Ella tiene el sentimiento de ser un "eslabón de una enorme cadena". Es necesario tener espíritu de equipo, saber comunicar, lo cual se facilita por la disposición de los espacios, "nadie queda encerrado en su pequeño recipiente"; es necesario permanecer discreto. Su función la pone en contacto con informaciones confidenciales: "son cosas que guardo para mí; si sé ciertas cosas que conciernen al futuro de la división o a lo que sea, pienso que hace parte de mi trabajo no decirle a nadie, ni siquiera a mi marido. Yo represento un ojo, un oído y dedos que golpean sobre la máquina, es todo, así es preciso ver las cosas, es la manera más sana de proceder".

Trabajar en la misma empresa facilita, a su vez, la colaboración de la pareja para enfrentar, conjuntamente, vida familiar y carrera profesional. El tiempo pasado en la casa, por la mañana y sobre todo al regreso del trabajo, exige una disciplina familiar tan rigurosa como la disciplina dedicada al tiempo de trabajo: "Intentamos hacer lo posible para conciliar los imperativos familiares con los imperativos profesionales, equilibrarnos entre los dos". A pesar de las diferencias de horarios, se obligan habitualmente a hacer juntos los trayectos en carro, dejando los niños en la guardería y en la escuela, y recogiéndolos al regreso. "Mientras uno está en el baño con uno, el otro debe hacer otra cosa, preparar comida, por ejemplo; no existe especialización entre nosotros; si uno de los niños tiene un poco más de ganas de estar con el papá o con la mamá, nos ponemos en función de ellos, nos adaptamos a su voluntad [...]; cada uno entiende perfectamente las exigencias que podemos tener, esto permite que nos organicemos silos niños están enfermos o si hay una prioridad en algún lugar. Sabemos muy bien lo que se debe hacer. Pienso que eso nos facilita enormemente la tarea".

Varias veces, cuando uno de sus hijos enfermó, ella se organizó para poder trabajar en casa: "Yo venía por la mañana, me enteraba del trabajo del día, tomaba un computador portátil y trabajaba en casa. No estaba en el lugar de trabajo efectivamente, pero mi trabajo pudo avanzar. Hice cosas que no siempre tengo tiempo de hacer cuando estoy aquí". Al contrario, le sucedió de ir a la oficina, excepcionalmente, el sábado, sin perder jamás, por otra parte, el sentido de los límites entre tiempo de trabajo y vida familiar: "Es preciso saber dónde se tiene que parar".

En las entrevistas, las mujeres, tal vez más que los hombres, son sensibles a los contrastes entre la entrega de sí exigida a todos y la competencia sistemática entre los agentes de producción con jóvenes interinos, dispuestos a todo para conservar su puesto, o entre los "ejecutivos formados por la empresa" con los titulados en las "grandes escuelas" 14 cuyas esposas, a menudo inactivas, pueden encargarse de la familia. La enfermera hace espontáneamente la relación entre la degradación de las condiciones de trabajo y la patología que ella puede observar a diario: "Vamos cada vez más hacia la depresión, tal vez

\footnotetext{
${ }^{14}$ Establecimiento de enseñanza superior caracterizado por una selección de ingreso a través de concurso o de títulos, por un alto nivel de estudios y por efectivos reducidos [nota de la traducción al portugués]. 
son las personas que envejecen; en la producción, diría que las personas se cansan, y esto se vuelve cansancio físico porque es duro, las líneas de producción se vuelven cada vez más difíciles. Se apoyan mucho en empleados temporales que, aunque les digan 'no tiene empleo, etc.', en algún lugar siempre guardan aquella pequeña esperanza; por tanto, cuando se tiene 18-20 años, si se es temporal y se trabaja duro, se hace que los otros se vean obligados a trabajar duro, hay un cansancio físico que se instala. $Y$ después, los ejecutivos caen cada vez más en depresión, porque ellos envejecen a los cuarenta años. No sé si usted vio la escalera que está en nuestro hall de entrada, pero en verdad, la carrera en la HP, realmente, a partir de los cuarenta años, usted está en lo alto de la escalera y después... no estaba previsto así, pero es simbólico, es bien gracioso, sí, en verdad, esta escalera estaba prevista para estar contra un muro[...] y como hicieron una vitrina atrás, fue relegada y, finalmente, se volvió muy simbólico, de cara al vacío..., podríamos escribir debajo: 'carrera HP”. 